\title{
Article \\ Exposure to Secondhand Heated-Tobacco-Product Aerosol May Cause Similar Incidence of Asthma Attack and Chest Pain to Secondhand Cigarette Exposure: The JASTIS 2019 Study
}

\author{
Yuki Imura ${ }^{1}$ and Takahiro Tabuchi ${ }^{2, *(D)}$ \\ 1 School of Medicine, Osaka University, Osaka 565-0871, Japan; gtmwj864@yahoo.co.jp \\ 2 Osaka International Cancer Institute, Osaka 541-8567, Japan \\ * Correspondence: tabuchitak@gmail.com; Tel.: +81-6-6945-1181
}

check for

updates

Citation: Imura, Y.; Tabuchi, T.

Exposure to Secondhand

Heated-Tobacco-Product Aerosol

May Cause Similar Incidence of

Asthma Attack and Chest Pain to Secondhand Cigarette Exposure: The JASTIS 2019 Study. Int. J. Environ. Res. Public Health 2021, 18, 1766. https:// doi.org/10.3390/ijerph18041766

Academic Editors: Vaughan W. Rees and David Ashley

Received: 16 January 2021

Accepted: 9 February 2021

Published: 11 February 2021

Publisher's Note: MDPI stays neutral with regard to jurisdictional claims in published maps and institutional affiliations.

Copyright: (c) 2021 by the authors. Licensee MDPI, Basel, Switzerland. This article is an open access article distributed under the terms and conditions of the Creative Commons Attribution (CC BY) license (https:// creativecommons.org/licenses/by/ $4.0 /)$.

\begin{abstract}
Although secondhand cigarette smoke is known to cause various health consequences, even the short-term effects of exposure to secondhand heated-tobacco-product (HTP) aerosol are unknown. The purpose of this study was to examine short-term symptoms related to secondhand HTP aerosol exposure. An internet-based self-reported questionnaire survey was conducted in 2019 as a part of the Japan Society and New Tobacco Internet Survey (JASTIS) study. In total, 8784 eligible respondents aged 15-73 years were analyzed. We examined the frequency (\%) of secondhand combustible cigarette smoke and HTP aerosol exposure, and the exposure-related subjective symptoms (sore throat, cough, asthma attack, chest pain, eye pain, nausea, headache, and other symptoms). Overall, $56.8 \%$ of those exposed to secondhand cigarette smoke had any subjective symptoms, compared to $39.5 \%$ of those exposed to HTP aerosol. Asthma attack and chest pain were reported more frequently when associated with secondhand HTP exposure (10.9 and 11.8\%, respectively) than with secondhand cigarette smoke exposure (8.4 and 9.9\%, respectively). Sore throat, cough, eye pain, nausea, and headache were also more frequently reported when associated with secondhand cigarette smoke than with secondhand HTP exposure. This is the first study to examine severe subjective symptoms such as asthma attacks and chest pains, and to suggest that respiratory and cardiovascular abnormalities could be related to secondhand heated-tobacco-product aerosol exposure. Further careful investigations are necessary.
\end{abstract}

Keywords: heated tobacco product; secondhand smoke; asthma attack; chest pain

\section{Introduction}

Secondhand tobacco smoke can cause a variety of health consequences, such as respiratory symptoms, impaired lung function, and coronary heart disease [1,2]. Therefore, combustible cigarette smoking in public spaces has been prohibited [3]. In response to this social situation, tobacco companies have launched heated tobacco products (HTP) such as IQOS, glo, and Ploom TECH. HTPs are electronic devices that heat leaf tobacco. Users inhale aerosol containing tobacco extract instead of smoke; the aerosol is then exhaled into the surrounding air. Chemical analyses have shown that secondhand HTP aerosol may have fewer particular detriments than secondhand combustible cigarette smoke [4]. However, the degree of harmfulness has been unclear [3]. In Japan 2019, the percentage of people who smoked habitually was 16.7\% [5], and that of HTP users was 11.3\% [6]. Secondhand exposure will have affected more people.

Evaluation of the long-term effects of secondhand exposure on chronic disease is difficult because HTPs are recent products. Even short-term effects have seldom been reported [7]. Our previous survey only examined non-severe subjective symptoms such as sore throat, eye pain, and nausea. Therefore, our objective in this study is to examine short-term but relatively severe subjective symptoms, including chest pain and asthma 
attacks, in relation to secondhand HTP and combustible cigarette exposure. This is the first study to examine such symptoms.

\section{Materials and Methods}

\subsection{Internet Survey}

The Japan "Society and New Tobacco" Internet Survey (JASTIS) is a longitudinal internet-based cohort study which was designed to investigate perception, attitude, and use of HTPs, electronic cigarettes (e-cigarettes), and conventional tobacco products in Japan. The surveys were conducted between 2 and 28 February 2019. Respondents were selected from a large survey panel managed by a major nationwide internet research agency, Rakuten Insight [8], and were invited to participate in the survey. The survey was closed when the target number of respondents who had answered the questionnaire was reached. In the present study, we used cross-sectional data from the survey conducted among 11,000 people. Detailed information on the study has been provided in previous publications $[7,9,10]$. Panelists who consented to participate in the survey accessed the designated website and responded to the questionnaire. The survey data including questionnaires and details methods information can be accessed via the corresponding author on reasonable request.

\subsection{Symptoms from Exposure to Secondhand Combustible Cigarette Smoke and HTP Aerosol}

Participants were asked for self-reported experience of inhaling smoke produced by other people, using the following question:

'Have you inhaled the smoke of combustible cigarettes that other people were smoking within this one year?' Response options were 'never, 1-4 times, or 5 or more times.'

Later, those who had inhaled smoke produced by other people were asked for selfreported symptoms due to secondhand exposure, using the following questions:

'Within this one year, have you experienced sore throat/cough/asthma attack/chest pain/eye pain/nausea/headache/other symptoms, after inhaling the smoke of combustible cigarette that other people were producing?' Response options were 'no, 1-4 times, or 5 or more times'.

Participants were also asked about secondhand HTP aerosol exposure using the questions that were applied to combustible cigarettes. Those who answered "1-4 times" or " 5 or more times" were combined as the experienced group. Symptoms of sore throat, cough, asthma attack, and chest pain were combined and categorized as any respiratory symptom; although chest pain can be derived from lung and heart, it was assumed to be a respiratory symptom in this study.

\subsection{Characteristic Variables}

Data for age group (15-19 years, 20-29, 30-39, 40-49, 50-59, 60-73), gender (man or woman), education (junior high school or high school, college or university and more), marital status (married, unmarried, and divorced or widowed), combustible-cigarette smoking status (non-smoker or current smoker), HTP using status (non-user or current user), and self-rated health (good or poor) were used as covariates. Married was defined as those who were married at the time of the survey; unmarried as those who had never married, and divorced or widowed. Current smoker or current HTP users were defined as those who had smoked or used HTPs in the previous 30 days. Self-rated health was dichotomized: good (excellent, very good, or good) or poor (fair or poor).

\subsection{Statistical Analysis}

Proportions of exposure to secondhand combustible cigarette and HTP and exposurerelated subjective symptoms were calculated according to characteristic variables, comparing the proportions by fisher exact tests. Multivariable analyses were used to document the 
adjusted relationship between the above-mentioned variables and experienced symptoms. All analyses were performed using STATA/MP 15.0 for Windows (Stata Corp LLC, College Station, TX, USA).

\section{Results}

\subsection{Percentages of Secondhand Exposure}

A total of 472 respondents who had discrepancies in their responses were excluded, leaving 8784 subjects aged 15-73 years. Table 1 shows the basic characteristics of the study subjects and the percentages of exposure to secondhand combustible cigarette smoke and secondhand HTP aerosol. For example, 5142 subjects (58.5\%) had been exposed to secondhand combustible cigarette smoke within the past year. Current smokers of combustible cigarettes or HTPs were more likely to be exposed to secondhand smoke or aerosols. Highly-educated (university or more) subjects were more likely to be exposed to secondhand smoke or aerosols than other groups. Subjects aged between 20-49 were more likely to be exposed to HTP aerosol than those aged over 50 .

\subsection{Symptoms Associated with Secondhand Exposure}

Tables 2 and 3 and Figure 1 show the percentage (\%) of subjects with self-reported symptoms associated with secondhand exposure. For example, $29.2 \%$ of those exposed to secondhand combustible cigarette smoke had experienced sore throat after inhaling the smoke and $23.0 \%$ of those exposed to secondhand HTPs aerosol had experienced sore throat after inhaling the aerosol. In total, $56.8 \%$ of those exposed to secondhand combustible cigarette smoke had any symptoms (sore throat, cough, asthma attack, chest pain, eye pain, nausea, headache, or other symptoms), compared with $39.5 \%$ of those exposed to HTP aerosol. The most common complaint was nausea (44.4\% related to cigarettes and $31.9 \%$ by HTPs). Non-smoker and non-HTP-user participants were separately analyzed (results of the stratified analysis are shown in Figure 1B). Overall, 3995 non-smoker and non-HTP-users exposed to second-hand cigarette smoke, and 2102 persons exposed to second-hand HTP aerosol were analyzed and the results showed almost the same trends as the total sample. As a general trend, young people were likely to be more vulnerable than the elderly; those with poor self-related health were also likely to be more vulnerable than those with good health. Current smokers of cigarettes or HTPs were less likely to experience symptoms than non-smokers, except for asthma attack and chest pain which were reported more among current smokers. 
Table 1. Secondhand exposure according to characteristics of study subjects, the JASTIS 2019, $n=8784$.

\begin{tabular}{|c|c|c|c|c|c|c|}
\hline & \multicolumn{2}{|c|}{ Total } & \multicolumn{2}{|c|}{$\begin{array}{c}\text { Secondhand Cigarette Smoke } \\
\text { Exposure }\end{array}$} & \multicolumn{2}{|c|}{$\begin{array}{c}\text { Secondhand HTP Aerosol } \\
\text { Exposure }\end{array}$} \\
\hline & $n$ & $\%$ & $n$ & $\%$ & $n$ & $\%$ \\
\hline $\begin{array}{l}\text { Total } \\
\text { Sex }\end{array}$ & 8784 & 100.0 & 5142 & 58.5 & 2923 & 33.3 \\
\hline Man & 4286 & 48.8 & 2583 & $60.3^{*}$ & 1606 & $37.5^{* *}$ \\
\hline Woman & 4498 & 51.2 & 2559 & 56.9 & 1317 & 29.3 \\
\hline \multicolumn{7}{|l|}{$\begin{array}{l}\text { Age group, } \\
\text { years }\end{array}$} \\
\hline 15-19 & 853 & 9.7 & 483 & $56.6^{* *}$ & 278 & $32.6^{* *}$ \\
\hline $20-29$ & 1539 & 17.5 & 883 & 57.4 & 606 & 39.4 \\
\hline $30-39$ & 1373 & 15.6 & 807 & 58.8 & 527 & 38.4 \\
\hline $40-49$ & 1650 & 18.8 & 1002 & 60.7 & 603 & 36.5 \\
\hline $50-59$ & 1507 & 17.2 & 952 & 63.2 & 501 & 33.2 \\
\hline $60-$ & 1862 & 21.2 & 1015 & 54.5 & 408 & 21.9 \\
\hline \multicolumn{7}{|l|}{$\begin{array}{l}\text { Current } \\
\text { cigarette } \\
\text { smoker }\end{array}$} \\
\hline No & 7482 & 85.2 & 4129 & $55.2 * *$ & 2267 & $30.3^{* *}$ \\
\hline Yes & 1302 & 14.8 & 1013 & 77.8 & 656 & 50.4 \\
\hline \multicolumn{7}{|l|}{$\begin{array}{l}\text { Current HTP } \\
\text { user }\end{array}$} \\
\hline No & 7993 & 91.0 & 4554 & $57.0 * *$ & 2412 & $30.2 * *$ \\
\hline Yes & 791 & 9.0 & 588 & 74.3 & 511 & 64.6 \\
\hline \multicolumn{7}{|l|}{ Education } \\
\hline $\begin{array}{c}\text { High } \\
\text { school/less }\end{array}$ & 2874 & 32.7 & 1616 & $56.2^{* *}$ & 868 & $30.2^{* *}$ \\
\hline 2-year-college & 1752 & 19.9 & 974 & 55.6 & 520 & 29.7 \\
\hline University/more & 4158 & 47.3 & 2552 & 61.4 & 1535 & 36.9 \\
\hline \multicolumn{7}{|l|}{ Marital status } \\
\hline Married & 4492 & 51.1 & 2674 & 59.5 & 1461 & $32.5 *$ \\
\hline Unmarried & 3740 & 42.6 & 2158 & 57.7 & 1302 & 34.8 \\
\hline $\begin{array}{l}\text { Divorced/widowed } \\
\text { Self-related } \\
\text { health }\end{array}$ & 552 & 6.3 & 310 & 56.2 & 160 & 29.0 \\
\hline Good & 7778 & 88.5 & 4568 & 58.7 & 2617 & $33.6 *$ \\
\hline Poor & 1006 & 11.5 & 574 & 57.1 & 306 & 30.4 \\
\hline
\end{tabular}

Abbreviations: JASTIS, the Japan "Society and New Tobacco" Internet Survey; HTP, heated tobacco product. Note: $p$ values for difference between statuses were obtained using chi-square or Fisher's exact tests. ${ }^{*} p<0.05,{ }^{* *} p<0.001$ The ${ }^{*}$ mark was only placed by the first covariate factor of the characteristic. 
Table 2. Respiratory symptoms related to cigarette smoke and HTP aerosol produced by others.

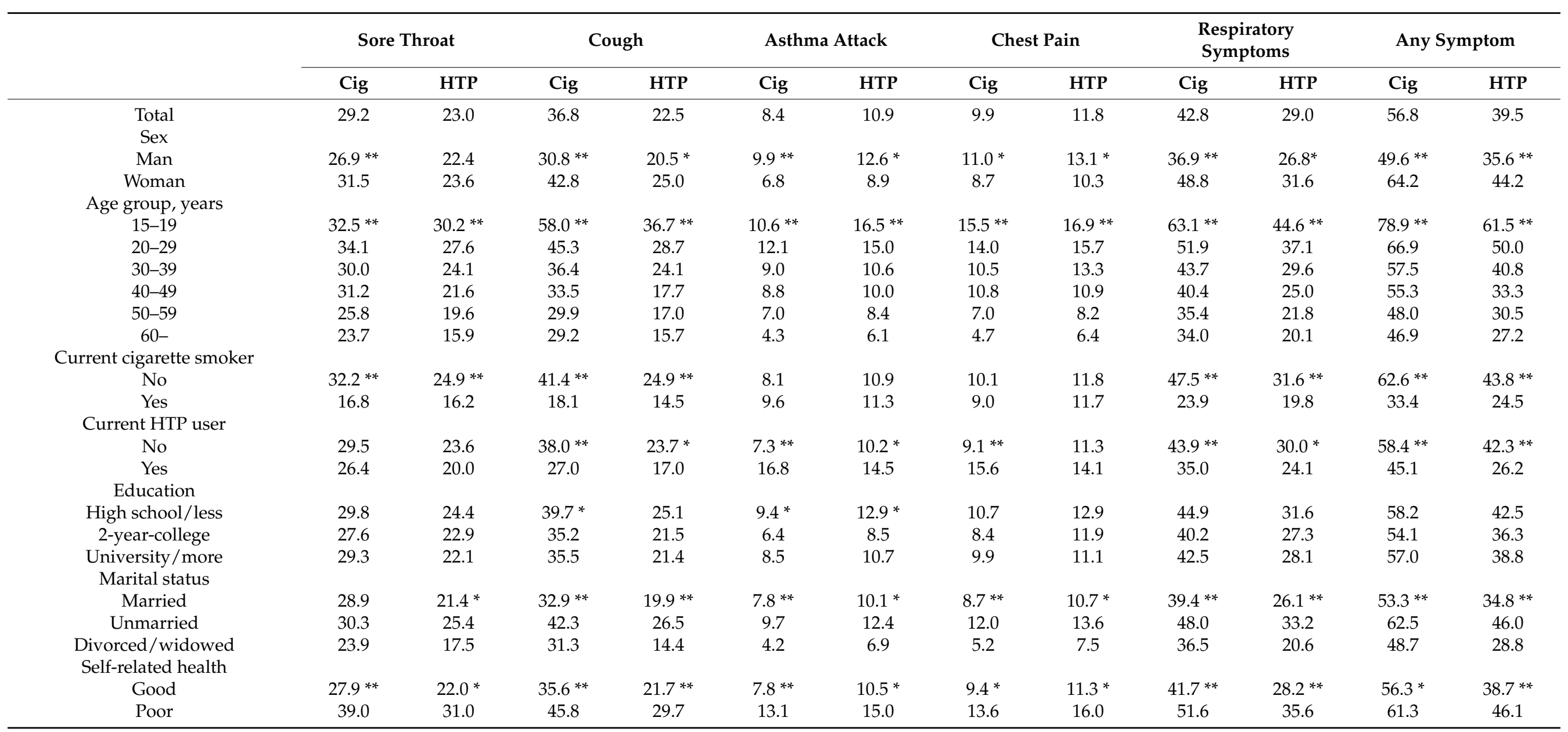

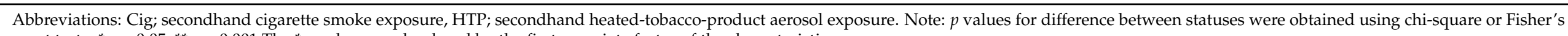
exact tests. ${ }^{*} p<0.05,{ }^{* *} p<0.001$ The ${ }^{*}$ mark was only placed by the first covariate factor of the characteristic. 
Table 3. Non-respiratory symptoms related to cigarette smoke and HTP aerosol produced by others.

\begin{tabular}{|c|c|c|c|c|c|c|c|c|}
\hline & \multicolumn{2}{|c|}{ Eye Pain } & \multicolumn{2}{|c|}{ Nausea } & \multicolumn{2}{|c|}{ Headache } & \multicolumn{2}{|c|}{ Other Symptoms } \\
\hline & Cig & HTP & Cig & HTP & Cig & HTP & Cig & НTP \\
\hline $\begin{array}{l}\text { Total } \\
\text { Sex }\end{array}$ & 28.2 & 19.3 & 44.4 & 31.9 & 19.8 & 17.7 & 9.5 & 12.0 \\
\hline Man & 28.0 & 20.1 & $37.8 * *$ & $29.1 * *$ & $18.0 *$ & 17.7 & $11.0^{* *}$ & $13.4^{*}$ \\
\hline Woman & 28.4 & 18.2 & 51.1 & 35.4 & 21.6 & 17.7 & 8.1 & 10.3 \\
\hline \multicolumn{9}{|l|}{ Age group, years } \\
\hline $15-19$ & $32.9^{* *}$ & $23.4^{* *}$ & $65.8 * *$ & $50.4^{* *}$ & $32.1 * *$ & $26.6^{* *}$ & $12.2^{* *}$ & $15.8^{* *}$ \\
\hline $20-29$ & 30.6 & 23.8 & 52.1 & 39.4 & 25.0 & 23.6 & 12.5 & 16.0 \\
\hline $30-39$ & 30.7 & 21.6 & 45.0 & 34.3 & 22.3 & 19.2 & 10.0 & 12.0 \\
\hline $40-49$ & 32.9 & 18.6 & 42.7 & 27.9 & 20.9 & 16.6 & 10.8 & 11.3 \\
\hline $50-59$ & 24.6 & 15.0 & 38.3 & 24.8 & 16.6 & 12.8 & 8.1 & 10.2 \\
\hline $60-$ & 20.5 & 13.0 & 34.5 & 19.9 & 9.4 & 8.6 & 5.5 & 6.9 \\
\hline \multicolumn{9}{|l|}{ Current cigarette smoker } \\
\hline No & $29.7^{* *}$ & $20.7^{* *}$ & $50.4^{* *}$ & $35.8 * *$ & $21.8^{* *}$ & $18.7 *$ & $10.0 *$ & 12.5 \\
\hline Yes & 22.1 & 14.3 & 20.0 & 18.6 & 11.7 & 14.3 & 7.8 & 10.2 \\
\hline \multicolumn{9}{|l|}{ Current HTP user } \\
\hline No & 27.9 & 19.7 & $46.1 * *$ & $34.5 * *$ & 19.7 & 17.7 & $8.9^{* *}$ & 11.7 \\
\hline Yes & 30.6 & 17.2 & 31.6 & 20.0 & 20.6 & 17.8 & 14.3 & 13.5 \\
\hline \multicolumn{9}{|l|}{ Education } \\
\hline High school/less & 29.3 & 19.7 & 44.7 & 34.6 & 21.2 & 19.4 & 9.5 & 12.8 \\
\hline 2-year-college & 25.6 & 17.9 & 41.7 & 30.6 & 17.8 & 16.3 & 8.4 & 11.0 \\
\hline University/more & 28.4 & 19.5 & 45.3 & 30.9 & 19.7 & 17.2 & 10.0 & 11.9 \\
\hline \multicolumn{9}{|l|}{ Marital status } \\
\hline Married & $27.0^{*}$ & $17.7 *$ & $41.3^{* *}$ & $27.6^{* *}$ & $17.5^{* *}$ & $15.4^{* *}$ & $8.8^{*}$ & 11.0 \\
\hline Unmarried & 30.2 & 21.9 & 49.2 & 37.8 & 23.2 & 21.1 & 10.9 & 13.4 \\
\hline $\begin{array}{l}\text { Divorced/widowed } \\
\text { Self-related health }\end{array}$ & 24.8 & 12.5 & 38.1 & 23.8 & 15.8 & 10.6 & 6.8 & 10.0 \\
\hline Good & $27.4^{* *}$ & $18.5^{*}$ & $43.7^{*}$ & $31.1 *$ & $19.1^{*}$ & $16.7^{* *}$ & $9.2 *$ & $11.6^{*}$ \\
\hline Poor & 34.5 & 25.5 & 50.3 & 38.6 & 25.3 & 26.5 & 12.4 & 15.7 \\
\hline
\end{tabular}

Abbreviations: Cig; secondhand cigarette smoke exposure, HTP; secondhand heated-tobacco-product aerosol exposure. Note: $p$ values for difference between statuses were obtained using chi-square or Fisher's exact tests. ${ }^{*} p<0.05,{ }^{* *} p<0.001$ The ${ }^{*}$ mark was only placed by the first covariate factor of the characteristic. 

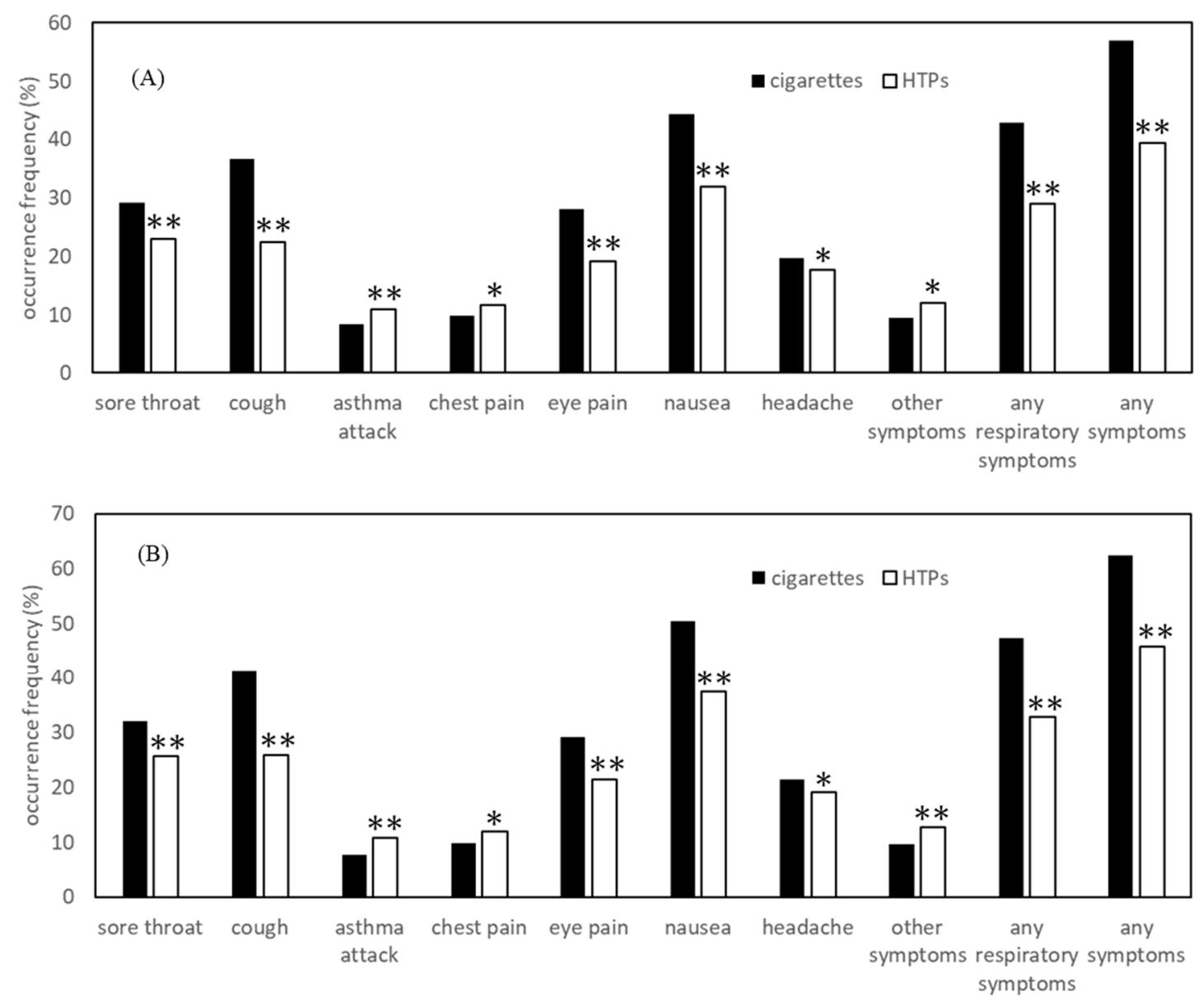

Figure 1. Occurrence ratio of symptoms from secondhand exposure among the whole sample (A), and among non-smoker and non-HTP-user participants (B). Occurrence ratio of sore throat, eye pain, nausea, cough was higher from secondhand cigarette smoke exposure than from secondhand HTP aerosol exposure. That of asthma attack and chest pain was higher from exposure to HTP aerosol than to cigarette smoke. ${ }^{*} p<0.05,{ }^{* *} p<0.001$.

\section{Discussion}

This is the first study to examine severe subjective symptoms such as asthma attacks and chest pains, which suggest respiratory and cardiovascular abnormalities related to secondhand HTP aerosol exposure. Surprisingly, compared to secondhand cigarette smoke, secondhand HTP aerosol exposure was more likely to be associated with asthma attacks and chest pains. On the other hand, in terms of relatively non-severe symptoms, sore throat and cough were less frequently related to secondhand HTP aerosol exposure than secondhand cigarette smoke, suggesting a small difference of approximately $20-30 \%$ between secondhand HTP and cigarettes exposure, which is consistent with our previous study [7].

Recent experimental studies indicate that HTP aerosol may be harmful, suggesting a possible mechanism. Of course, cigarette smoke can cause asthma and cardiovascular abnormalities including angina [2]. Exposure to cigarette smoke enhances sensitization to allergens and can bypass or override the normal tolerogenic response to inhaled antigen in mice [2]. Nicotine is vasoconstrictive [11], which may cause chest pain. Chemical analysis revealed that the amounts of harmful compounds, such as nicotine, in HTP aerosol were smaller than those in cigarette smoke $[4,12,13]$. However, it has not been confirmed that they were smaller than the threshold for attacks. It is known that even the smallest amount of tobacco smoke may cause toxic effects [2]. Moreover, several harmful compounds such as 2-furanmethanol were detected at higher levels in HTP aerosol than in smoke [13]. 2furanmethanol is known as an irritant, thus, it might be related to asthma attacks and chest 
pain. An in vitro bioassay using respiratory cell lines suggested that higher concentrations of IQOS aerosol showed cytotoxicity equivalent to combustible cigarette smoke [14].

While HTPs operate differently than electronic cigarettes (e-cigarettes), reported health effects may be similar [15]. The aerosol from e-cigarettes has caused sore throat, cough, patho-physiological cardiovascular effects or airway obstructions [16,17]. An epidemiological study showed that adolescent e-cigarette users had increased rates of chronic respiratory symptoms [18]. Another study suggested increased odds of asthma among never combustible e-cigarette users [19]. Although it is unlikely to be associated with a single e-cigarette brand or compound, e-cigarette- or vaping-associated lung injury (EVALI) has been reported, at least suggesting that e-cigarettes can cause severe health outcomes including pneumonia and death [20].

This survey might reveal information about changes in the second-hand-exposure status of combustible cigarettes in recent years. For example, highly educated people reported where they encounter second-hand smoke, which was not seen in previous reports [21]. This may be because there are many large companies (employing educated people) in Japan that provide a separate area for smoking in the workplace rather than operating a complete smoking ban in large companies [22].

There are several limitations to the study. First, although the research agency seeks to ensure representativeness, the distribution is always imperfect; for example, there are no data of those who do not use internet. Additionally, self-reported information was used, and we excluded respondents with discrepancies or inconsistencies in the answers. Second, HTPs look like electronic cigarettes. Electronic cigarettes use liquid instead of tobacco leaf, and nicotine-containing liquid is prohibited in Japan. Some people might categorize HTPs, such as IQOS, as an electronic cigarette such as Juul, and vice versa. Therefore, some might have interchangeably selected both electronic cigarettes and HTPs, and this may have led to misclassification. Third, in some cases, the symptoms might be severe, others might recover rapidly. These situations may differ due to underlying comorbidities, which were not assessed in the survey. Such differences were not considered in this study, but will be included in future research. Similarly, the level of second-hand exposure could not be measured, thus a quantitative analysis could not be performed in this study. Further studies should better quantify exposure time and severity to evaluate a possible dose-response relationship. Fourth, because self-reported information is based on memory and subjective impression, there might issues of uncertainty. For example, the elderly are more likely to forget their experience, thus, the general trend that young people were likely to be more vulnerable than the elderly could be due, in part, to better recollection of their experience. Another example is that smokers or users of HTPs might not perceive symptoms as strongly because they do not perceive the harm from the products to be as severe since they use them. A previous study reported that adolescents who used electronic cigarettes had more favorable impression of them than those who did not use e-cigarettes [23]. Such problems of recall or user bias are possible. However, the results of non-smoker and no HTP user in this study (Figure 1B) were almost same to those of whole population (Figure 1A), suggesting that the user bias might not strongly influence the results. Fifth, several important issues could not be investigated in this survey. For example, the experience of acute symptoms related to second-hand exposure by others has been investigated, but the extent to which similar symptoms occurred with no second-hand exposure has not. Therefore, the degree to which second-hand exposure increases acute symptoms is unknown. This study examined experiences within one year, suggesting a risk of coincidental symptoms. Therefore, we will try next study using a definite period of time (for example one week or one month). Finally, this research used cross-sectional data, making it difficult to consider causal inference. The causal relationship between respiratory diseases and HTP should be clarified by longitudinal studies in the future. 


\section{Conclusions}

HTPs are sometimes considered to pose lower health risks than cigarettes. However, asthma attack and chest pain were related to secondhand HTP exposure more frequently than secondhand cigarette smoke exposure. This is the first study to examine severe symptoms such as asthma attacks and chest pains, and to suggest that respiratory and cardiovascular abnormalities could be related to secondhand HTP aerosol exposure. Further study should better define and quantify this potential relationship.

Author Contributions: T.T. had full access to all of the study data and takes responsibility for the integrity of the data and the accuracy of the data analysis. Study concept and design: Y.I., T.T. Acquisition of data: T.T. Analysis and interpretation of data: Y.I., T.T. Drafting of the manuscript: Y.I. Statistical analysis: Y.I., T.T. Study supervision: T.T. All authors have read and agreed to the published version of the manuscript.

Funding: This research was funded by Health Labor Sciences Research Grants (19-FA1-005, 19-FA1011, 19-FA2-001, and 20FA0501) and the Japan Society for the Promotion of Science (JSPS) KAKENHI Grants (15K19256 and 18H03062).

Institutional Review Board Statement: The study was reviewed and approved by the Research Ethics Committee of the Osaka International Cancer Institute (no. 1412175183) and the National Institute of Public Health (NIPH-IBRA\#12112).

Informed Consent Statement: Internet-based informed consent was obtained from all subjects involved in the study.

Data Availability Statement: The data used in this study are not available in a public repository because they contain personally identifiable or potentially sensitive patient information. Based on the regulations for ethical guidelines in Japan, the Research Ethics Committee of the Osaka International Cancer Institute has imposed restrictions on the dissemination of the data collected in this study. All data enquiries should be addressed to the person responsible for data management, Dr. Takahiro Tabuchi at the following e-mail address: tabuchitak@gmail.com.

Acknowledgments: The authors would like to thank Julia Mortimer for her English-language editing.

Conflicts of Interest: The funders had no role in the design of the study; in the collection, analyses, or interpretation of data; in the writing of the manuscript, or in the decision to publish the results.

\section{References}

1. US Department of Health and Human Services. The Health Consequences of Involuntary Exposure to Tobacco Smoke: A Report of the Surgeon General 2006; US Department of Health and Human Services: Washington, DC, USA, 2006.

2. US Department of Health and Human Services. The Health Consequences of Smoking-50 Years of Progress: A Report of the Surgeon General 2014; US Department of Health and Human Services: Washington, DC, USA, 2014.

3. World Health Organization. WHO Report on the Global Tobacco Epidemic, 2019; World Health Organization: Geneva, Switzerland, 2019.

4. Simonavicius, E.; McNeill, A.; Shahab, L.; Brouse, L.S. Heat-not-burn tobacco products: A systematic literature review. Tob. Control 2019, 28, 582-594. [CrossRef] [PubMed]

5. Ministry of Health, Labor and Welfare National Health and Nutrition Examination Survey. Available online: https://www.mhlw. go.jp/stf/newpage_14156.html (accessed on 23 November 2020).

6. Hori, A.; Tabuchi, T.; Kunugita, N. Rapid increase in heated tobacco product (HTP) use from 2015 to 2019: From the Japan 'Society and New Tobacco' Internet Survey (JASTIS). Tob. Control 2020. [CrossRef] [PubMed]

7. Tabuchi, T.; Gallus, S.; Shinozaki, T.; Nakaya, T.; Kunugita, N.; Colwell, B. Heat-not-burn tobacco product use in Japan: Its prevalence, predictors and perceived symptoms from exposure to secondhand heat-not-burn tobacco aerosol. Tob. Control 2018, 27, e25-e33. [CrossRef] [PubMed]

8. Kato, T.; Endo, A. Involving citizens in sharing disaster experiences across areas: An investigation into disaster-stricken communities and observing communities. Int. J. Disaster Risk Reduct. 2020, 42, 101378. [CrossRef]

9. Tabuchi, T.; Shinozaki, T.; Kunugita, N.; Nakamura, M.; Tsuji, I. Study Profile: The Japan “Society and New Tobacco" Internet Survey (JASTIS): A Longitudinal Internet Cohort Study of Heat-Not-Burn Tobacco Products, Electronic Cigarettes, and Conventional Tobacco Products in Japan. J. Epidemiol. 2019, 29, 444-450. [CrossRef] [PubMed]

10. Kiyohara, K.; Tabuchi, T. Use of heated tobacco products in smoke-free locations in Japan: The JASTIS 2019 study. Tob. Control 2020. [CrossRef] [PubMed] 
11. Perkins, K.A.; Epstein, L.H.; Jennings, J.R.; Stiller, R. The cardiovascular effects of nicotine during stress. Psychopharmacology 1986, 90, 373-378. [CrossRef] [PubMed]

12. Uchiyama, S.; Noguchi, M.; Takagi, N.; Hayashida, H.; Inaba, Y.; Ogura, H.; Kunugita, N. Simple determination of gaseous and particulate compounds generated from heated tobacco products. Chem. Res. Toxicol. 2018, 31, 585-593. [CrossRef] [PubMed]

13. St Helen, G.; Jacob, P.; Nardone, N.; Benowitz, N.L. IQOS: Examination of Philip Morris International's claim of reduced exposure. Tob. Control 2018, 27, s30-s36. [CrossRef] [PubMed]

14. Davis, B.; To, V.; Talbot, P. Comparison of cytotoxicity of IQOS aerosols to smoke from Marlboro Red and 3R4F reference cigarettes. Toxicol. In Vitro 2019, 61, 104652. [CrossRef] [PubMed]

15. Stephens, W.E. Comparing the cancer potencies of emissions from vapourised nicotine products including e-cigarettes with those of tobacco smoke. Tob. Control 2017, 27, 10-17. [CrossRef] [PubMed]

16. Pisinger, C.; Døssing, M. A systematic review of health effects of electronic cigarettes. Prev. Med. 2014, 69, 248-260. [CrossRef] [PubMed]

17. Shields, P.G.; Berman, M.; Brasky, T.M.; Freudenheim, J.L.; Mathe, E.; McElroy, J.P.; Song, M.A.; Wewers, M.D. A review of pulmonary toxicity of electronic cigarettes in the context of smoking: A focus on inflammation. Cancer Epidemiol. Biomark. Prev. 2017, 26, 1175-1191. [CrossRef] [PubMed]

18. McConnell, R.; Barrington-Trimis, J.L.; Wang, K.; Urman, R.; Hong, H.; Unger, J.; Samet, J.; Leventhal, A.; Berhane, K. Electronic cigarette use and respiratory symptoms in adolescents. Am. J. Respir. Crit. Care Med. 2017, 195, 1043-1049. [CrossRef] [PubMed]

19. Osei, A.D.; Mirbolouk, M.; Orimoloye, O.A.; Dzaye, O.; Uddin, S.M.I.; Dardari, Z.A.; DeFilippis, A.P.; Bhatnagar, A.; Blaha, M.J. The association between e-cigarette use and asthma among never combustible cigarette smokers: Behavioral risk factor surveillance system (BRFSS) 2016 \& 2017. BMC Pulm. Med. 2019, 19, 180. [CrossRef]

20. Layden, J.E.; Ghinai, I.; Pray, I.; Kimball, A.; Layer, M.; Tenforde, M.W.; Navon, L.; Hoots, B.; Salvatore, P.P.; Elderbrook, M.; et al. Pulmonary Illness Related to E-Cigarette Use in Illinois and Wisconsin-Preliminary Report. N. Engl. J. Med. 2020, 382, 903-916. [CrossRef] [PubMed]

21. Tabuchi, T.; Nakamura, M. Disparity of secondhand smoke exposure at home and/or workplace according to age, education and medical insurance in Japan. JACR Monogr. 2014, 20, 39-48.

22. Tabuchi, T.; Hoshino, T.; Nakayama, T. Are Partial Workplace Smoking Bans as Effective as Complete Smoking Bans? A National Population-Based Study of Smoke-Free Policy among Japanese Employees. Nicotine Tob. Res. 2016, 18, 1265-1273. [CrossRef] [PubMed]

23. Gorukanti, A.; Delucchi, K.; Ling, P.; Fisher-Travis, R.; Halpern-Felsher, B. Adolescents' attitudes towards e-cigarette ingredients, safety, addictive properties, social norms, and regulation. Prev. Med. 2017, 94, 65-71. [CrossRef] [PubMed] 